\title{
Correction to: Robust Valuation, Arbitrage Ambiguity and Profit \& Loss Analysis
}

\author{
Yu-Hong $\mathrm{Xu}^{1}$
}

(C) Operations Research Society of China, Periodicals Agency of Shanghai University, Science Press, and Springer-Verlag GmbH Germany, part of Springer Nature 2018

\section{Correction to: J. Oper. Res. Soc. China https://doi.org/10.1007/s40305-017-0181-3}

In the original publication of the article, the fund note was incorrectly published. The correct fund note is provided in this article. The author was supported by the National Natural Science Foundation of China (No. 11401414) and the Natural Science Foundation of Jiangsu Province (Nos. BK20140299 and 14KJB110022).

The original article can be found online at https://doi.org/10.1007/s40305-017-0181-3.

$\triangle \quad$ Yu-Hong Xu yuhong.xu@hotmail.com

1 Mathematical Center for Interdiscipline Research and School of Mathematical Sciences, Soochow University, Suzhou 215006, China 